the second dose of the drug was taken. Dr. F. Sinclair (British Medical Journal) said that from his observation with this medicament he was satisfied that it deserved a permanent place among the analgesics, as being one that was prompt in action, was safe, and could always be relied upon. By giving it in broken doses of from 0.03 to 0.06 it was free from any danger of producing intoxication. If after the first dose the pain was not relieved, it should be repeated in one-half hour; it was seldom that four doses had to be given consecutively. The class of patients to which this drug was most applicable were those persons of neurotic temperaments, suffering with pain of a functional character and also pain from dietetic causes. Pain of an organic or mechanical nature was not influenced by exalgine. During the recent epidemic of influenza this drug exerted marked alleviation on the attending paroxysms of pain. In angina pectoris its influence for good was very noticeable. Henry Semple (ibid.), in treating an hysterical patient for nervous headache, gave as large dose as 0.12 twice daily and increased it to 0.3 , with the effect of the pain being absent for eight hours at a time. On the recurrence of the headache two doses were given in quick succession with the result, in fifteen minutes, of a sudden scream and the patient saying she was dying. The skin and fingers became numb, there was nystagmus, with intermittent numb feeling in the head and a very heavy sensation in the region of the diaphragm. After a few moments emesis took place, with a very marked improvement in the general condition of the patient. Sleep followed. The pain in the head came on again in two hours, the numbness continued in the fingers for the whole day. So that the author concludes that for the drug to be safe it should not be given in greater quantities than o.I2.

\title{
THE TREATMENT OF NEURALGIAS WITH CHLORMETHYL.
}

The "Deutsche med. Wochenschrift" contains an article by Steiner on the benefits to be derived from the use of this material in the treatment of the several neuralgic conditions which yield so obstinately to the known remedies. The chlormethyl $\left(\mathrm{CH}_{3} \mathrm{CL}\right)$, or monochlormethane, originally a gas, becomes fluid through the pressure of four atmospheres; in this condition it is carried into copper syphons. An apparatus is fitted to the bottle by which means the chlormethyl is allowed to escape as a thick cloud directly against the painful part to be treated. The part becomes as cold as 
if the application had been made with ice; at no time has this been followed by gangrene; at the most, only causing a red spot on the skin. The remedy not alone lowers the temperature, but also the excitability of the sensory nerves and in this way acts as an important agent in lessening and dissipating pain. As a local anxsthetic the remedy is well known in France, where it has been used with considerable success by Debove. Steiner prefers this application in the neuralgias to quinine, antipyrine or phenacetine, etc., and says that massage and electricity may be used in conjunction with it. The application is made daily, the looked-for result is attained at once, and the pain does not return after the first week of treatment. He has so treated several very severe cases of ischiatic neuralgia, traumatic neuroses, pruritus vulvæ, and trigeminal neuralgia, and from the good results obtained is able to advocate its use very highly.

B. M.

\section{TREATMENT OF INFANTILE PARALYSIS.}

Dr. Simon, the renowned Paris specialist in children's diseases, recommends the following treatment for infantile paralysis: At first counter-irritation along the vertebral column at the points corresponding to the roots of the paralyzed nerves. At the same time stimulate the functions of the skin by warm baths or vapor baths, given to the child in bed.

Chloral, aconite and conium are used to calm the nervous excitement.

After the first week electricity should form the basis of the treatment. Weak galvanic currents should be used, the negative pole being placed in a basin of water, into which the hand is plunged, while the positive pole is applied labile to the arm and shoulder. Length of treatment eight to ten minutes.

Later, faradism is to be used, but always with the greatest prudence.

W. F. R.

\section{ON THE EMPLOYMENT OF EXALGINE IN}

\section{INFANTILE THERAPEUTICS.}

Dr. Moncorvo's researches have been carried out on a total of twenty-one children from the age of one and a half years to twelve. In all these cases the exalgine was given to combat the element of pain, and exceeded his expectations. In fact, in not a single case was he disappointed in its effects, and in every instance tolerance was perfect. 